\title{
Simulator Sistem Pengairan Otomatis Tanaman Hidroponik Dengan Arduino
}

\author{
Dwi Haryanto ${ }^{1}$, Nurwijayanti $\mathrm{KN}^{1}$
}

\begin{abstract}
Hydroponics is a method of farming without using soil as a planting medium. There are several types of hydroponics techniques, one of them is nutrient film technique (NFT) which uses water media containing nutrients, and the water flows thinly on average $0.5 \mathrm{~mm}-3 \mathrm{~mm}$, as thin as a film. Water circulation time is measured starting from time the water pump turned on until the water returns to the bottom storage tank. The time obtained is 280.8 seconds. The discharge time of water that is the time for the upper storage tank $(400 \mathrm{ml})$ to run out is 129.4 seconds. The water circulation time starting from the upper storage tank until it reaches the bottom storage tank is 191.2 seconds.
\end{abstract}

KEYWORDS : Hydroponics, Nutrient Film Technique, Arduino

\begin{abstract}
ABSTRAK : Hidroponik yaitu metode bercocok tanam tanpa menggunakan tanah sebagai media tanamnya. Terdapat beberapa macam teknik dalam hidroponik salah satunya adalah Nutrient Film Technique (NFT) dimana sistem ini menggunakan media air yang mengandung nutrisi, dan air tersebut mengalir tipis rata-rata $0.5 \mathrm{~mm}-3 \mathrm{~mm}$, tipis seperti film. Didapat waktu air sirkulasi dari saat pompa air ON sampai air kembali ke tangki penampungan bawah yaitu 280,8 detik. Waktu debit air dalam tangki penampungan atas (400 ml) habis yaitu 129,4 detik. Waktu air sirkulasi dari tangki penampungan atas ke tangki penampungan bawah yaitu 191,2detik.

Kata kunci : Hidroponik, Nutrient Film Technique, Arduino
\end{abstract}

\section{PENDAHULUAN}

$\mathrm{M}$ asyarakat Indonesia sejak zaman dahulu bermata pencaharian sebagai petani akan tetapi dengan pesatnya pertumbuhan penduduk, banyak sekali lahan pertanian berubah menjadi lahan perumahan ataupun perindustrian. Dengan kondisi demikian maka banyak orang yang tidak bisa bertani dan berkebun yang akhirnya mereka pasrah menjadi buruh. Keinginan dan minat yang sangat tinggi dalam bercocok tanam tetap ada dalam jiwa mereka, tetapi kendala lahan dan tempat yang sudah sempit serta tanah yang kurang subur menjadi kendala bagi sebagian besar masyarakat yang ingin bercocok tanam terutama untuk masyarakat yang tinggal di perkotaan. Perkembangan teknologi akhirnya bisa menemukan cara bercocok tanam yang tidak lagi harus menggunakan tanah sebagai media tanam. Salah satunya adalah bertanamsecara hidroponik.

Salah satu metode hidroponik dikenal dengan nama NFT. Kependekan dari Nutrient Film Technique adalah sistem hidroponik dengan cara mengalirkan lapisan tipis air pada akar tanaman sehingga tanaman bisa mendapatkan nutrisi yang tepat dengan kadar oksigen yang cukup. Hal ini menjadikan tanaman cepat tumbuh. Salah satu kelemahan sistem NFT adalah bila pompa nutrisi mati sehingga air nutrisi tidak mengalir ke akar tanaman. Kendala kedua adalah bila terjadi hujan, maka nutrisi akan kelebihan air, hal ini menyebabkan larutan nutrisi encer. Larutan yang encer akan menjadikan tanaman kekurangan pasokan nutrisi.

Untuk mengatasi masalah tersebut maka dibuatlah suatu sistem pengairan yang dapat mengendalikan sirkulasi air pada saat pompa tidak mendapatkan power listrik dan sistem pengairan yang dapat mengendalikan kelebihan air pada tangki penampungan bawah saat kondisi sedang hujan. Maka dari itu dibuatlah simulator sistem pengairan otomatis tanaman hidroponik dengan arduino.

\section{HIDROPONIK}

Hidroponik adalah budidaya menanam dengan dengan memanfaatkan air tanpa menggunakan tanah dengan menekankan pada pemenuhan kebutuhan nutrisi bagi tanaman. Kebutuhan air pada hidroponik lebih sedikit daripada kebutuhan air pada budidaya dengan tanah. hidroponik menggunakan air yang lebih efisien, jadi cocok diterapkan pada daerah yang memiliki pasokan air yang terbatas.

Dalam kajian bahasa, hidroponik berasal dari kata Hydro yang berarti air dan ponos yang berarti kerja. Jadi, hidroponik memiliki pengertian secara bebas teknik bercocok tanam dengan menekankan pada pemenuhan kebutuhan nutrisi bagi tanaman, atau dalam pengertian sehari-hari bercocok tanam tanpa tanah. Dari pengertian ini terlihat bahwa munculnya teknik bertanam secara hidroponik diawali oleh semakin tingginya perhatian manusia akan pentingnya kebutuhan pupuk bagi tanaman.

Dimana pun tumbuhnya sebuah tanaman akan tetap dapat tumbuh dengan baik apabila nutrisi (unsur hara) yang dibutuhkan selalu tercukupi. Dalam konteks ini fungsi dari tanah adalah untuk penyangga tanaman dan air yang ada merupakan pelarut nutrisi, untuk kemudian bisa diserap tanaman. Pola pikir inilah yang akhirnya melahirkan teknik bertanam dengan hidroponik, dimana yang ditekankan adalah pemenuhan kebutuhannutrisi.

Teknik hidroponik banyak dilakukan dalam skala kecil sebagai hobi dikalangan masyarakat Indonesia. Pemilihan jenis tanaman yang akan dibudidayakan untuk skala usaha komersial harus diperhatikan, karena tidak semua hasil pertanian bernilai ekonomis. Jenis tanaman yang mempunyai nilai ekonomi tinggi untuk dibudidayakan di hidroponik yaitu paprika, tomat, timun jepang, melon, terong jepang, dan selada.

\footnotetext{
${ }^{1}$ Program Studi Teknik Elektro Universitas Marsekal Suryadarma
} 


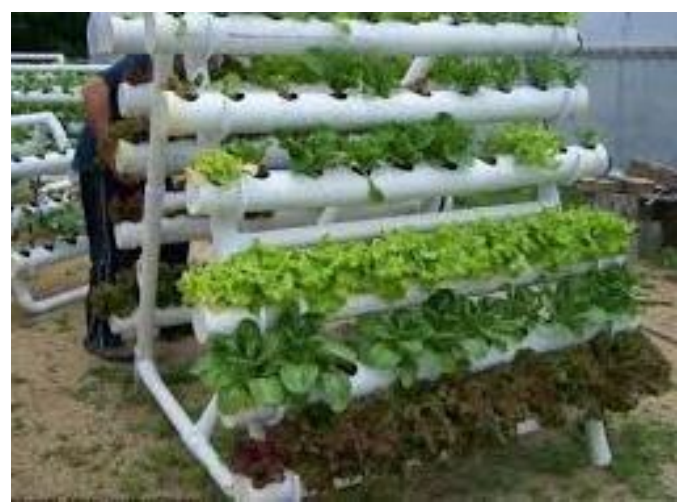

- Gambar 1. Tanaman Hidroponik

\section{NUTRIENT FILM TECHNIQUE}

NFT (Nutrient Film Technique) adalah adalah salah satu sistem dalam budidaya secara hidroponik. Sistem ini menggunakan media air yang mengandung nutrisi, dan air tersebut mengalir tipis rata-rata $0.5 \mathrm{~mm}-$ $3 \mathrm{~mm}$, tipis seperti film. Sedangkan akar terendam sebagian. Tetapi sistem ini pun sudah sangat berkembang dan di modifikasi dengan berbagai teknik, sebagian besar aliran air nutrisi tanaman mengalir dan kembali lagi di alirkan (circulating). Hidroponik NFT pertama kali muncul di Inggris pada tahun 1970, dan mulai masuk di Indonesia tahun 1992. Teknologi hidroponik, menawarkan cara bercocok tanam yang lebih baik dan cerdas. Teknik berkebun yang lebih mudah dan murah, bahkan di lahan sempit sekalipun. Tanaman hidroponik bersifat sistem, mudah dipindah-pindah, mudah diaplikasikan, dan sistem bebas perawatan. Kebanyakan bertani secara hidroponik sedikit menggunakan air dan produksinya lebih cepat, dengan hasil yang besar, tentunya dalam lingkungan yang bebas hama. Segalanya dikerjakan menggunakan bahan portable yang mudah di rakit.

Dalam teknik NFT atau teknik lapisan tipis, tanaman ditumbuhkan pada saluran (pipa) yang mana larutan nutrisi dipompa untuk melewatinya. Akar-akar tanaman dijaga agar tetap basah dengan selapis tipis larutan nutrisi yang melewatinya. Biasanya saluran NFT dialiri nutrisi terus menerus pada kecepatan sekitar 1 liter per menit. Di kebanyakan sistem NFT, larutan nutrisi dicampur pada penampung utama (reservoir), berputar melewati saluran dan kembali ke penampung. Dengan beberapa pengembangan, reservoir nutrisi sistem diatur secara otomatis, begitu juga aerasi dan pengaturan Ph-nya. NFT ideal untuk lettuce, sayuran daun, herba, dan semua tanaman berumur pendek. Untuk sayuran berumur panjang, saluran NFT harus dibuat lebih besar.

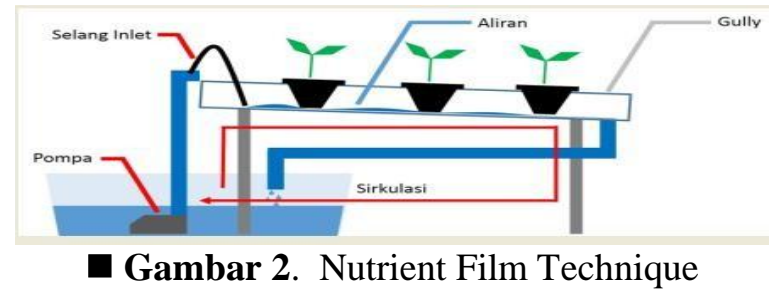

\section{ARDUINO UNO}

Adalah prototipe elektronika untuk chip mikrokontroler yang bersifat open source. Sampai saat ini software arduino terus dikembangkan, begitu juga dengan board arduino. Saat ini telah banyak beredar dengan bebas board yang kompatibel dangan arduino, bahkan beberapa diantaranya telah dilengkapi dengan fasilitas yang lebih baik dan lengkap dibanding dengan yang board arduino aslinya.

Uno berasal dari bahasa italy yang berarti satu. Arduino uno merupakan board yang menggunakan chip mikrokontroler Atmega328 sebagai pusat kendalinya. Arduino uno mempunyai 14 pin digital input/output, juga dilengkapi dengan 6 input analog, osilator eksternal dengan menggunakan kristal 16MHz, konektor USB, jack untuk power supply, header untuk ICSP, dan tombol reset.

Arduino uno dapat diberi sumber tegangan dengan menggunakan USB dari komputer maupun menggunakan power supply tambahan melalui jack power. Jika daya listrik yang dibutuhkan lebih dari 500 mA, sebaiknya menggunakan power supply eksternal bukan terminal USB. Pada arduino uno telah dilengkapi dengan fasilitas pemilihan sumber listrik secara otomatis.

Sampai saat ini tim arduino telah melakukan beberapa kali revisi arduino uno, sehingga kehandalan board lebih terjamin. Biasanya walaupun ada pembaharuan board arduino, fungsi dan cara kerja serta penggunaannya tetap sama. Posisi serta nama fitur yang terdapat pada board arduino uno dapat dilihat pada gambar berikut. 


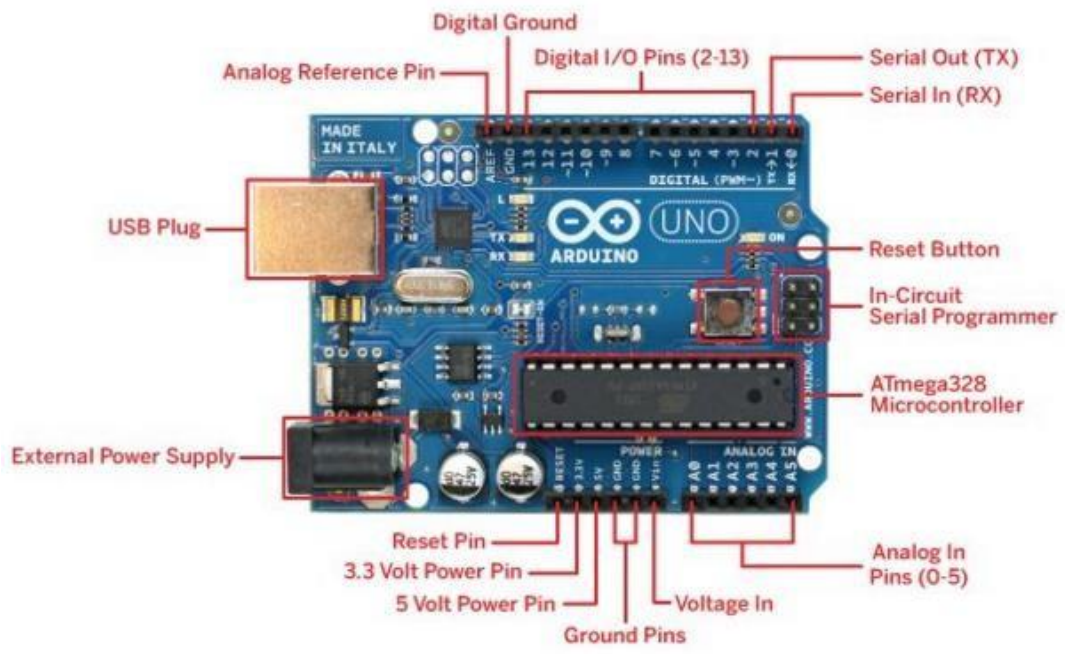

- Gambar 3. Board Arduino Uno

DIAGRAM BLOK

Sistem pengairan Hidroponik berbasis mikrokontroler ini menggunakan beberapa komponen utama seperti Arduino uno dan Pompa Air serta beberapa komponen pendukung seperti Power Supply, Sensor Hujan, Sensor Level Air, Relay Modul dan Selenoid Valve. Diagram blok untuk sistem pengairan hidroponik ditunjukkan seperti gambar dibawah ini :

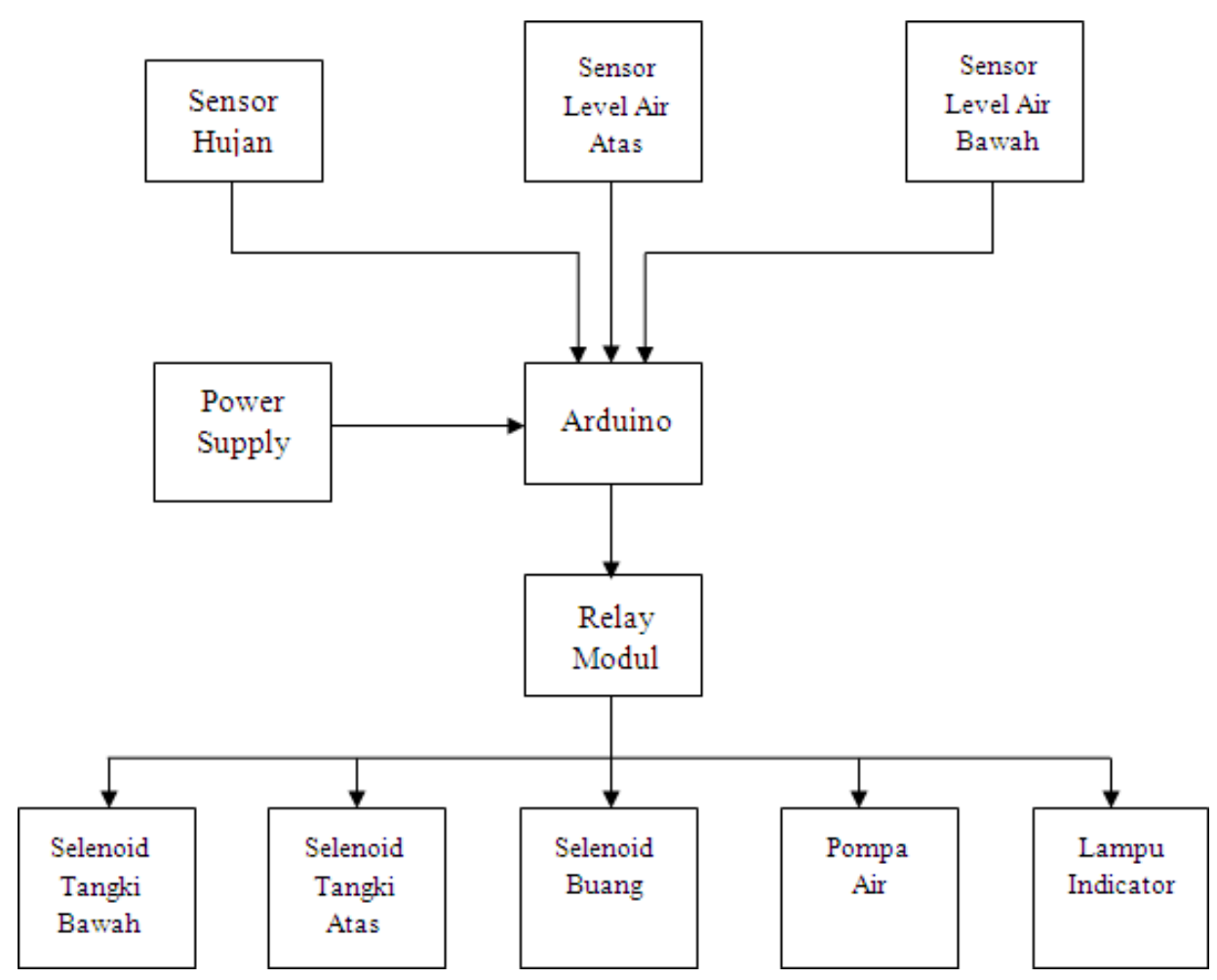

- Gambar 4. Diagram Blok Sistem Pengairan Hidroponik 


\section{FLOWCHART}

Flow chart sistem pengairan hidroponik akan dijelaskan seperti gambar berikut ini.

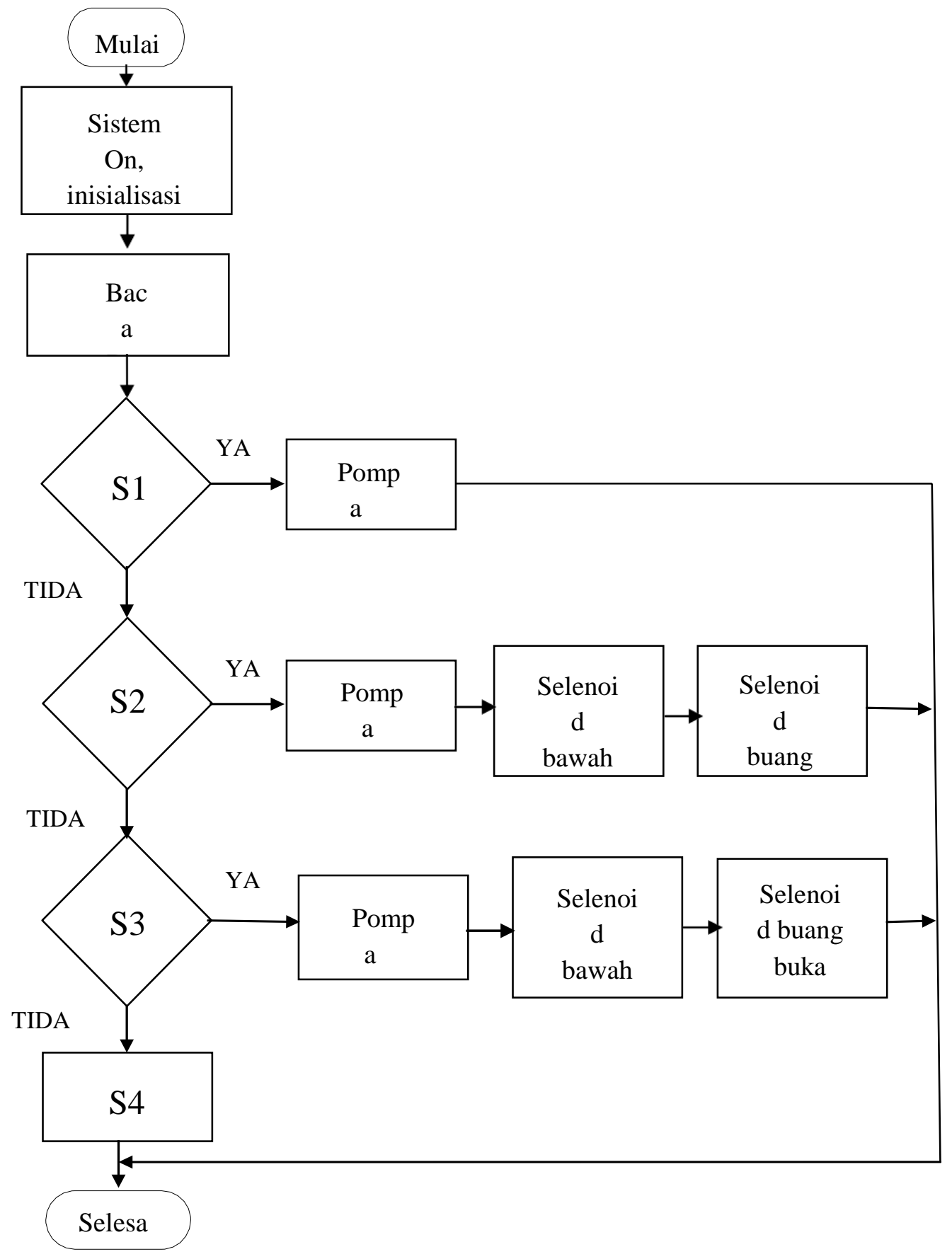

- Gambar 5. Flow Chart Sistem Pengairan Hidroponik

Keterangan :

S1 adalah kondisi tangki kosong S2 adalah kondisi tangki penuh

S3 adalah kondisihujan

$\mathrm{S} 4$ adalah kondisi normal 


\section{PERANCANGAN ALAT}

Perancangan alat tersebut meliputi beberapa bagian, yaitu : pembuatan program pada Arduino, pembuatan rangkaian wiring antar komponen ke komponen, pembuatan rangka untuk komponen, setting sensitivitas sensor dan setting kecepatan pompa air untuk penyesuaian rangkaian yang telah ada.

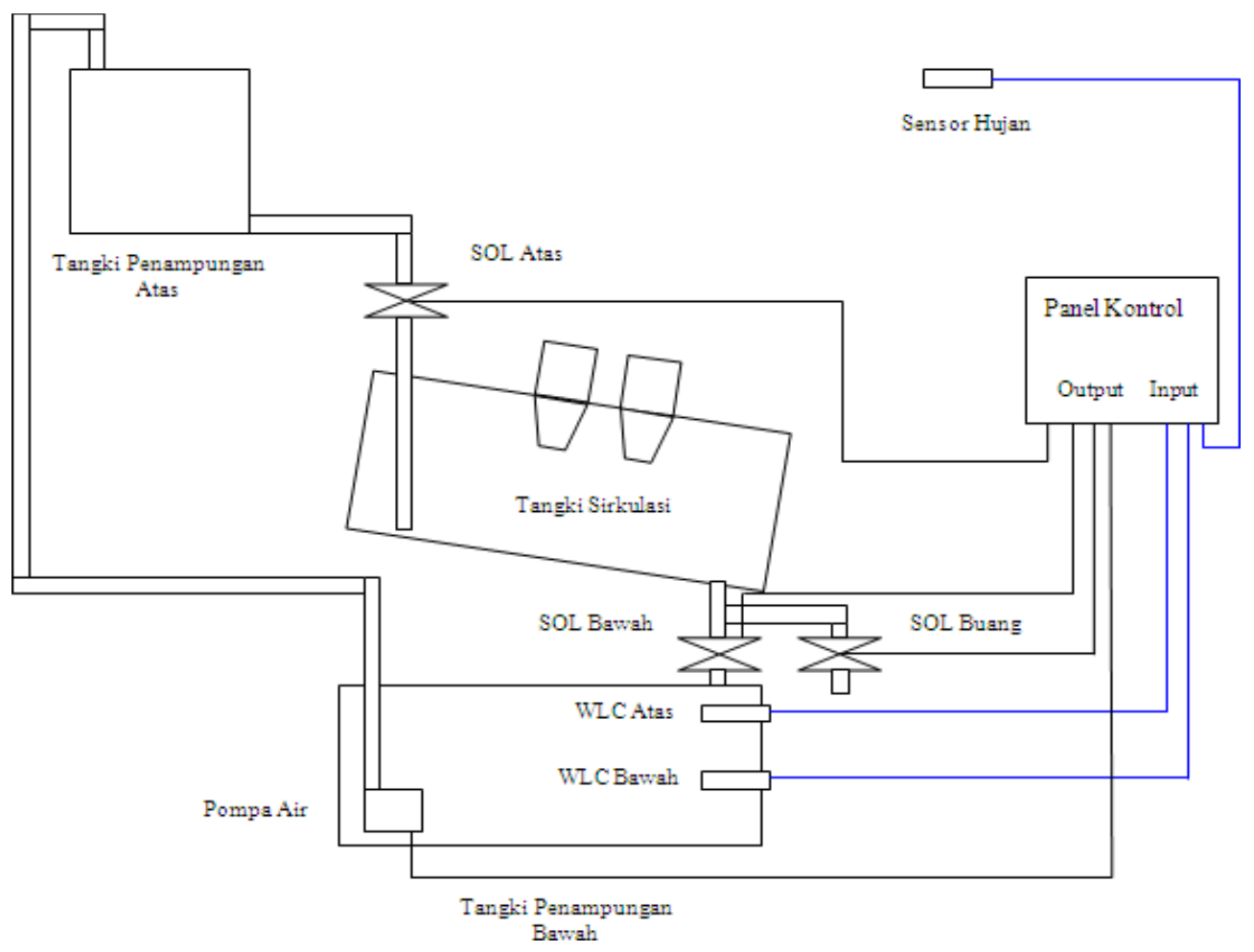

Gambar 6. Line Diagram Pengairan Hidroponik

\section{Perancangan Rangkaian Wiring Komponen}

Pembuatan rangkaian ini membutuhkan beberapa komponen pendukung seperti kabel kontrol, kabel power, terminal kabel, baut pcb serta peralatan pendukung seperti tang, obeng, multitester dan sebagainya. Untuk ukuran kabel disesuaikan dengan jarak antara komponen-komponen tersebut. Didalam wiring tersebut terdapat 2 sumber tegangan yaitu tegangan AC $220 \mathrm{~V}$ dan tegangan DC 24 V. Tegangan DC dibutuhkan oleh komponen Arduino, Relay, Sensor Hujan dan WLC. Tegangan AC dibutuhkan oleh Power Supply, Selenoid, dan Pompa Air. 


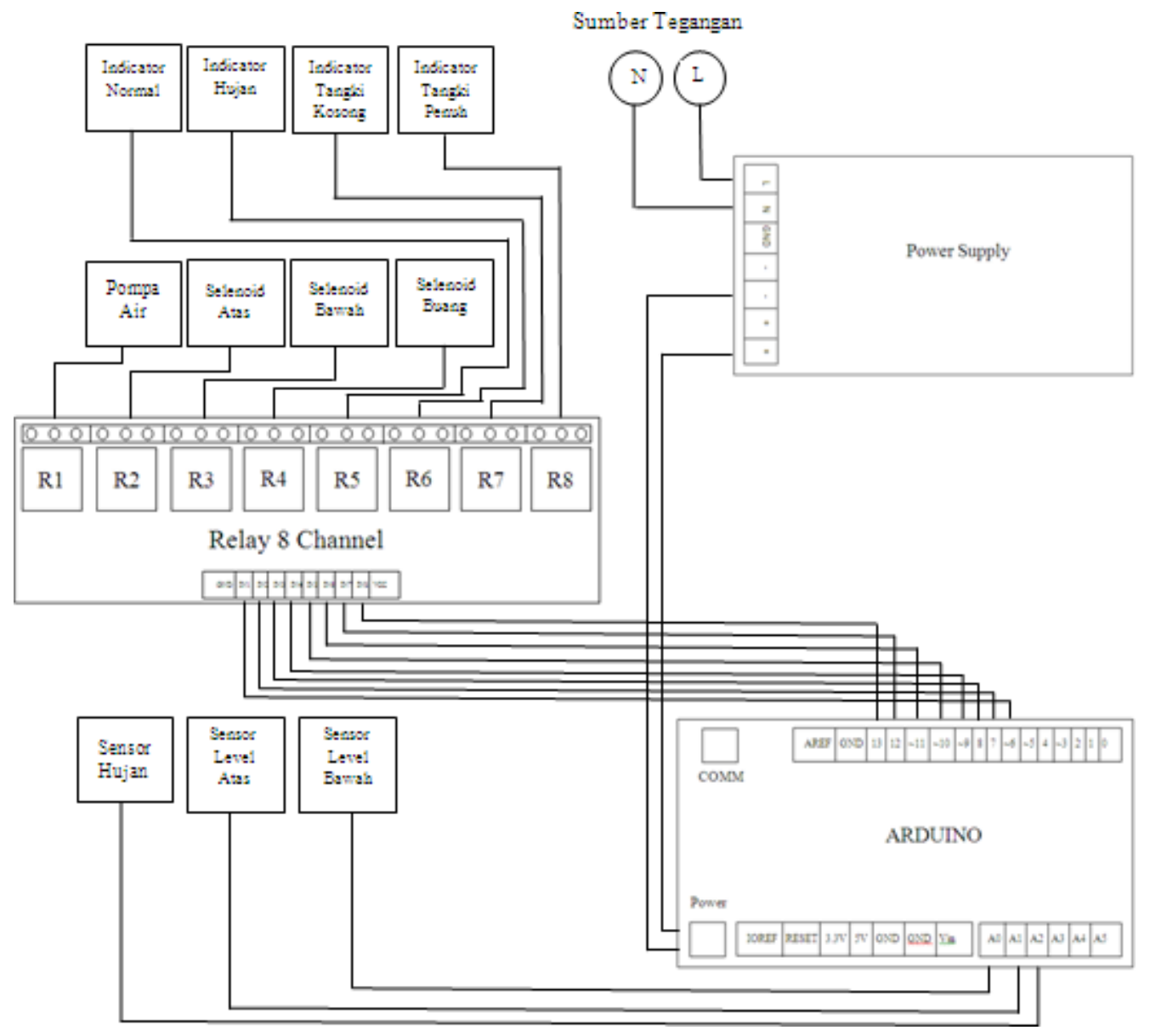

- Gambar 7. Rangkaian Wiring antar Komponen

\section{Perancangan Tangki Air Tangki Penampungan Bawah}

Desain tangki menggunakan Tupperware berukuran $25 \mathrm{~cm}$ x $9.5 \mathrm{~cm}$ x $10 \mathrm{~cm}$. Pada penutup tangki bagian atas dibuatkan 2 buah lubang. Lubang pertama digunakan untuk memasang selang ke tangki penampungan atas dan lubang kedua digunakan untuk pemasangan selang dari tangki sirkulasi. Pada sisi sebelah kanan juga dibuatkan 2 buah lubang untuk pemasangan sensor air batas bawah danatas.

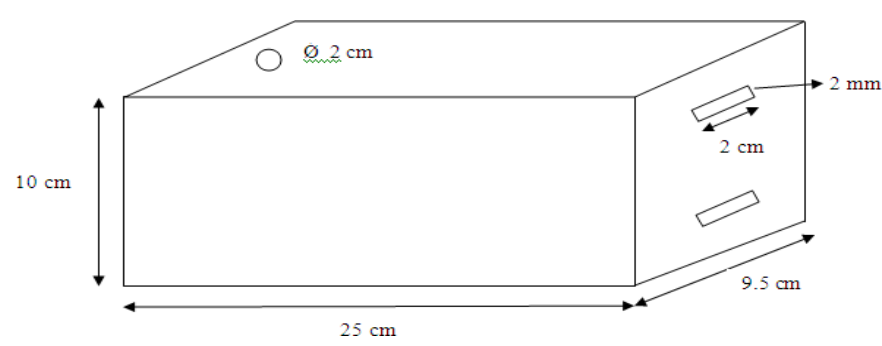

- Gambar 8. Tangki Penampungan Bawah 


\section{Tangki PenampunganAtas}

Desain tangki menggunakan Tupperware berukuran $9 \mathrm{~cm} \times 6 \mathrm{~cm} \times 9 \mathrm{~cm}$. Pada penutup tangki bagian atas dibuatkan 1 buah lubang untuk pemasangan selang dari tangki penampungan bawah yang dari pompa air, dan 1 buah lubang pada posisi sisi kanan bawah untuk pemasangan selang ke tangki sirkulasi.

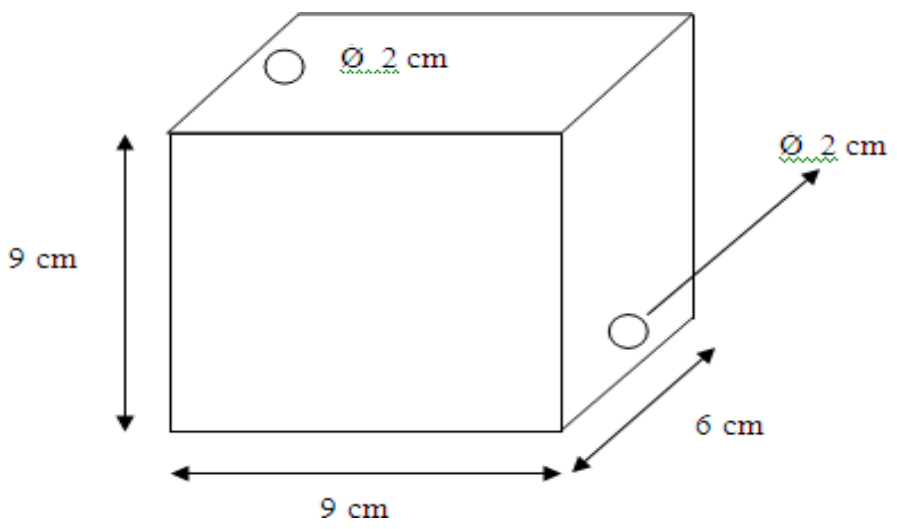

- Gambar 9. Tangki Penampungan Atas

\section{Tangki Sirkulasi}

Desain tangki menggunakan Tupperware berukuran $25 \mathrm{~cm} \times 9.5 \mathrm{~cm}$ x $10 \mathrm{~cm}$. Pada tangki sirkulasi ini akan ditempatkan 2 pot untuk tanaman berukuran @ diameter $65 \mathrm{~cm}$. Pada bagian atas tangki akan dibuatkan lubang untuk pemasangan selang dari tangki penampungan atas dan pada bagian bawah tangki juga akan dibuatkan lubang untuk pemasangan selang ke tangki penampunganbawah.
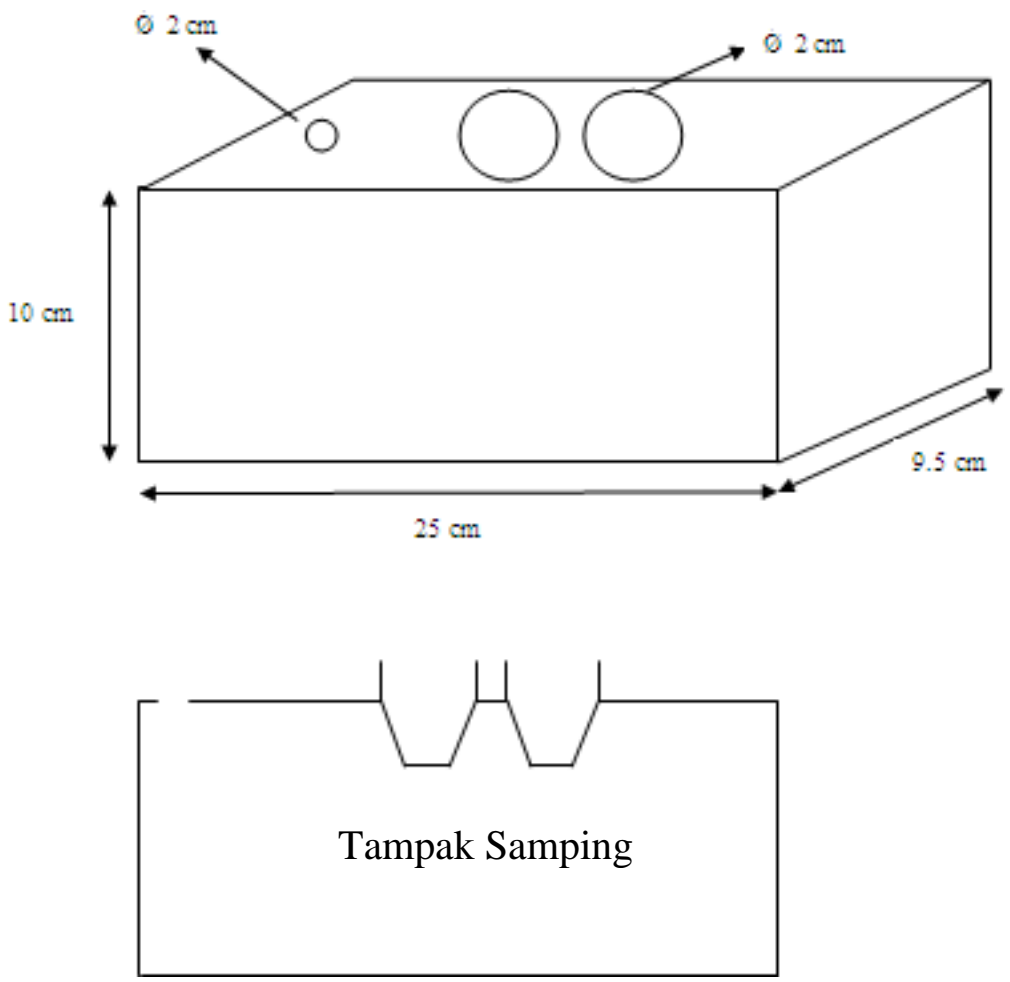

- Gambar 10. Tangki Sirkulasi 
PENGUJIAN ALAT

Setelah semua alat dirangkai maka dilakukan pengujian secara keseluruhan sistem sebagai berikut:

1. Sistem dinyalakan dalam kondisi normal, lalu dihitung waktu air sirkulasi dari saat pompa air On sampai air kembali ke penampungan bawah.

Tabel 1. Waktu Sirkulasi 1

\begin{tabular}{|r|r|r|}
\hline Pengujian & Waktu (detik) & Waktu (menit) \\
\hline 1 & 280 & 4.67 \\
\hline 2 & 284 & 4.73 \\
\hline 3 & 278 & 4.63 \\
\hline 4 & 283 & 4.72 \\
\hline 5 & 279 & 4.65 \\
\hline Rata2 & 280,8 & 4.68 \\
\hline
\end{tabular}

Dari tabel pengujian diatas dilakukan 5 kali lalu diambil rata-rata waktunya menjadi 280,8 detik atau 4,68 menit.Jadi waktu yang dibutuhkan untuk 1 kali sirkulasi air dari tangki penampungan bawah ke tangki penampungan atas lalu masuk ke tangki sirkulasi dan kembali ke tangki penampungan bawah adalah 280,8 detik.

2. Sistem dinyalakan dalam kondisi normal, sampai debit tangki penampungan atas penuh (400 $\mathrm{ml})$ lalu dihitung waktu berapa lama debit air dalam tangki penampungan atashabis.

- Tabel 2. Waktu Debit Tangki Penampungan Atas

\begin{tabular}{|r|r|r|}
\hline Pengujian & Waktu (detik) & Waktu (menit) \\
\hline 1 & 130 & 2.17 \\
\hline 2 & 125 & 2.08 \\
\hline 3 & 134 & 2.23 \\
\hline 4 & 127 & 2.12 \\
\hline 5 & 131 & 2.18 \\
\hline Rata2 & 129.4 & 2.16 \\
\hline
\end{tabular}

Dari tabel pengujian diatas dilakukan 5 kali lalu diambil rata-rata waktunya menjadi 129,4 detik atau 2,16 menit.Jadi waktu yang dibutuhkan untuk air pada tangki penampungan atas (400 ml) habis yaitu 129,4 detik.

3. Sistem dinyalakan dalam kondisi normal, sampai debit tangki penampungan atas penuh (400 ml) lalu sistem dimatikan dan dihitung waktu air sirkulasi dari tangki penampungan atas sampai air masuk ke tangki penampungan bawah. 
- Tabel 3. Waktu Sirkulasi 2

\begin{tabular}{|r|r|r|}
\hline Pengujian & Waktu (detik) & Waktu (menit) \\
\hline 1 & 191 & 3.18 \\
\hline 2 & 194 & 3.23 \\
\hline 3 & 189 & 3.15 \\
\hline 4 & 192 & 3.2 \\
\hline 5 & 190 & 3.17 \\
\hline Rata2 & 191,2 & 3.19 \\
\hline
\end{tabular}

Dari tabel pengujian diatas dilakukan 5 kali lalu diambil rata-rata waktunya menjadi 191,2 detik atau 3,19 menit . Jadi waktu yang dibutuhkan untuk air sirkulasi dari tangki penampungan atas lalu masuk ke tangki sirkulasi dan kembali ke tangki penampungan bawah adalah 191,2 detik.

\section{KESIMPULAN}

1. Waktu air sirkulasi dari saat pompa air On sampai air kembali ke tangki penampungan bawah yaitu 280,8 detik atau 4,68menit.

2. Waktu debit air dalam tangki penampungan atas (400 ml) habis yaitu 129,4 detik atau 2,16menit.

3. Waktu air sirkulasi dari tangki penampungan atas sampai air masuk ke tangki penampungan bawah yaitu 191,2 detik atau 3,19menit.

\section{DAFTAR PUSTAKA}

[1] Bishop, Owen, Dasar-dasar Elektronika. Jakarta:Erlangga, 2002.

[2] Djuandi, Feri,Pengenalan Arduino. Jakarta:Alexmedia , 2011.

[3] Lingga, P. Hidroponik, Bercocok Tanam Tanpa Tanah. Jakarta: PenebarSwadaya, 2006.

[4] Rangkuti, Syahban, Arduino \& Proteus Simulasi DanPraktik.Bandung: Informatika, 2016.

[5] Satria, Regi, Pengertian Relay Elektronika. Yogyakarta: PenerbitAndi, 2011.

[6] Untung, O. HidroponikSayuran Sistem NFT (Nutrient Film Technique). Bogor: PenebarSwadaya, 1999.

[7] Yulianto, Agus,Perancangan Monitoring Dan Controlling Water Level Control Berbasis HMI Menggunakan PLC Dan Pompa Air 3 Fasa. Jakarta, 2012.

[8] https://id.wikipedia.org/wiki/Arduino/(21 Juli2017)

[9] https://id.wikipedia.org/wiki/Sensor/(3 Agustus2017)

[10] http://www.sabah.org.my/bm/nasihat/artikel pertanian/hidroponik.htm(16 Agustus 2017) 